\title{
0 texto em verso no desenvolvimento da competência lexical em aula de português língua estrangeira
}

Palabras clave: texto em verso, léxico, vocabulário, competência lexical, português língua estrangeira

The fact is that while without grammar very little can be conveyed, without vocabulary notbing can be conveyed

David Arthur Wilkins (1972)

\section{Introdução}

Percorrendo alguns estudos acerca da exploração didática de textos literários, entre eles, o texto em verso, compreendemos que a sua inclusão em aula de língua estrangeira (LE) tem variado no último século, consoante o enfoque metodológico predominante. A nosso ver, a utilização da literatura com um fim didático e a crescente revalorização do texto em verso como recurso didático no processo de ensino-aprendizagem de uma LE e não como objeto de estudo literário, representa um assunto de máxima atualidade, nomeadamente no campo anglo-saxónico e da língua espanhola.

A natureza metafórica do género poético, a acumulação de significações implícitas e explícitas e a abundância de imagens poéticas que permitem a exploração de diferentes temáticas lexicais e do léxico presente no poema, favorecem o desenvolvimento da competência lexical. Para além disso, sendo a poesia capaz de sensibilizar o ser humano, poderá contribuir para a formação pessoal dos aprendentes. 
Acreditamos nos benefícios da interdependência entre a língua e a literatura em aula de LE e que a aprendizagem de uma língua será mais eficaz se a competência lexical for trabalhada em sala de aula. No presente artigo, demonstramos como a competência lexical de aprendentes de uma LE pode ser desenvolvida através do texto em verso.

\section{Léxico e competência lexical}

Uma vez que o presente artigo tem como foco o desenvolvimento da competência lexical, começamos por apresentar e refletir sobre estes conceitos. De acordo com Vilela (1994: 1995), o léxico de uma língua é entendido como o conjunto das palavras que dela fazem parte e em ambas as perspetivas (cognitivo-representativa e comunicativa) trata-se da codificação de um saber partilhado. Para além disso, o léxico pode ser considerado um sistema aberto, quase imprevisível e infinito e é utilizado pelo falante para a formação do seu vocabulário e para a sua própria expressão no momento do processo comunicativo. Vilela (1995: 13) define o conceito de vocabulário como uma «subdivisão do léxico»e como as palavras que pertencem a um «determinado lugar e num determinado tempo, tempo e lugar ocupados por uma comunidade linguística». Desta forma, o léxico caracteriza-se pela sua generalidade, encontrando-se associado ao social e ao essencial, enquanto que o vocabulário compreende o particular, o individual e o acessório.

Uma língua viva é uma língua heterogénea e ativa que reflete a diversidade dos grupos sociais que a falam. O léxico é a parte da língua que configura a realidade extralinguística e arquiva o saber linguístico de uma comunidade e constitui, assim, uma das componentes que sofre mais consequências provocadas pela mudança linguística. Este traço dinâmico do sistema lexical traduz-se em processos de metáfora e metonímia relevantes para a presente investigação, que permitem a criação de novos significados para significantes já existentes no sistema linguístico. Com efeito, torna-se impensável não contemplar a dimensão lexical no processo de ensino-aprendizagem de uma LE.

A natureza multifacetada das palavras dificulta a atribuição de uma definição simples de competência lexical. Meara (1996) faz referência à dificuldade em recolher todas as dimensões possíveis da competência lexical através de um só modelo teórico, até porque não são totalmente conhecidas, considerando inviáveis as aplicações didáticas que derivam de um modelo teórico desta natureza. Por conseguinte, o autor centra-se no estudo das características 
fundamentais e enumera duas dimensões que permitem medir a competência lexical: a organização lexical (entendida como associações entre as palavras e a forma como estas associações são organizadas) e a extensão (metodologia da checklist), relacionando estas características com o domínio da língua-alvo:

The basic dimension of lexicon competence is size. All other things being equal, learners with big vocabularies are more proficient in a wide range of language skills than learners with smaller vocabularies, and there is some evidence to support the view that vocabulary skills make a significant contribution to almost all aspects of L2 proficiency. (Meara, 1996: 3)

$\mathrm{Na}$ opinião do autor, terá mais sucesso na comunicação aquele falante ou aprendente que possui um vocabulário maior e mais estruturado, do que aquele que possui um número menor de itens sem estruturação.

A organização lexical diz respeito ao grau de conhecimento de uma palavra: «Most people seem to accept that alongside measures of how many words people know, we also need independent measures of how well these words are known» (Meara, 1996: 10).

Jiménez Catalán (2002) confere um carácter universal à competência lexical como conhecimento cumulativo de palavras (como um armazém mental) e não como a capacidade mental de as gerar. Acrescenta que a competência lexical se centra nas palavras da língua-alvo e não no aprendente da línguaalvo e tem por base dimensões de natureza gramatical e semântica. A mesma autora defende que o número de palavras que conforma a competência lexical varia ao longo do tempo e aponta a transversalidade da competência lexical face a outras competências, revelando a importância do léxico no processo de ensino-aprendizagem de uma LE, desde a sua relação com a dimensão linguística (fonológica, morfológica, sintática e semântica), até à dimensão sociolinguística, que implica não só o conhecimento da dimensão linguística, como também o uso de determinados aspetos de uma palavra num determinado contexto. Baralo (2007: 41) ressalva, de igual forma, o carácter transversal da competência lexical:

De forma resumida y a efectos prácticos, podemos describir la competencia léxica como una subcompetencia transversal, que contiene información codificada correspondiente a la forma de las palabras (fonética, fonológica, ortográfica, ortoépica, morfológica), a su función sintáctica (categoría y función), a 
su significado real o figurado (semántica), así como a su variación (sociolingüística) y a su valor intencional y comunicativo (pragmática).

Para a mesma autora, a competência lexical está relacionada e mediatizada pelo conhecimento do mundo do falante e pelas suas competências gerais. Consequentemente, o processo de ensino-aprendizagem de uma LE deve incluir a aprendizagem do léxico paralelamente com o contacto com a realidade e com outros conteúdos programáticos.

Neste sentido, a sua função não se centra apenas na expansão da bagagem lexical dos estudantes, mas também nos seus conhecimentos concernentes às características e funcionamento de palavras, como unidades e em todas as suas dimensões, de forma a que os alunos adquiram a capacidade para empregar cada palavra tendo em conta o registo, a precisão e a sua carga conotativa na situação comunicativa em causa (Cassany, Luna \& Sanz, 1994: 379).

\subsection{A competência lexical no Quadro Europeu Comum de Referência para as Línguas}

Em primeiro lugar, julgamos importante apresentar a definição de competência, que segundo o QECR - Quadro Europeu Comum de Referência para as Linguas (Conselho da Europa, 2001: 29) representa o «conjunto dos conhecimentos, capacidades e características que permitem a realização de ações». O QECR define a competência lexical que, por sua vez, se encontra inserida no campo da competência linguística e que, em conjunto com a competência sociolinguística e a competência pragmática, formam a competência comunicativa.

A competência linguística é apresentada como «o conhecimento de recursos formais a partir dos quais se podem elaborar e formular mensagens correctas e significativas, bem como a capacidade de as usar» (Conselho da Europa, 2001: 157), enquanto que, a competência lexical «Consiste no conhecimento e na capacidade de utilizar o vocabulário de uma língua e compreende elementos lexicais e gramaticais» (ibidem: 59). A competência semântica ocupa-se do significado das unidades lexicais, tanto em relação ao contexto geral (referência, conotação, noções específicas), como às relações semânticas entre elas. Neste sentido, a competência lexical permite que o usuário da língua reconheça a polissemia de uma unidade lexical - ou seja, os seus distintos sentidos - e atribuir-lhe um significado e um sentido adequado, de acordo com o contexto de uso. O QECR integra, de igual forma, uma escala para a amplitude vocabular 
e para o seu domínio, onde são enumerados os respetivos descritores para cada um dos níveis de proficiência de língua. Através da análise dos descritores alusivos à amplitude do vocabulário, é possível observar que, segundo o QECR, a competência lexical se desenvolve de uma forma gradual e que tem início no nível inicial de aprendizagem, terminando no nível máximo de proficiência, que engloba os aspetos conotativos do significado.

O QECR considera tanto a extensão lexical do aprendente, como o domínio sobre as estruturas lexicais, demonstrando uma visão qualitativa e quantitativa perante o desenvolvimento da competência lexical. Estas escalas ilustrativas de gradação do conhecimento do vocabulário da língua-alvo servem como critérios de reflexão, seleção, de decisões didáticas e de avaliação da competência léxica dos aprendentes.

É importante mencionar que as escalas demonstram a relação do léxico com as situações de comunicação, tornando-se indispensáveis desde o momento da seleção e produção de atividades que propõem o desenvolvimento da competência lexical, ao seu ensino e subsequente avaliação dos conhecimentos dos aprendentes.

\subsection{Estratégias para o desenvolvimento da competência lexical em aula de língua estrangeira}

Antes da enumeração das estratégias para o desenvolvimento da competência lexical em LE, importa recordar o processo de aquisição das unidades lexicais que, de acordo com Aitchinson (apud Morante, 2005: 46), consiste em três fases: primeiramente, verifica-se o fenómeno do reconhecimento de uma unidade léxica em que o aprendente retém a grafia e a relação entre a forma e o significado; numa segunda fase o aprendente descobre os possíveis significados da unidade léxica (denotativos, conotativos, figurativos), assim como as suas possibilidades morfológicas e sintáticas; e, finalmente, a unidade léxica passa a integrar o léxico mental do aluno e a formar parte do seu vocabulário passivo a longo prazo, permitindo a organização do léxico mediante redes semânticas e hierárquicas. Cervero e Pichardo (2000: 97) acrescentam uma quarta fase que consiste na recuperação do léxico adquirido, mediante a sua expressão verbal ou textual, passando a fazer parte do vocabulário ativo. É possível constatar que desde um primeiro momento do processo de ensino-aprendizagem os alunos de uma LE tentarão organizar o léxico aprendido de forma a que o possam armazenar e recuperar com rapidez. Seguindo esta lógica, é necessário ter em 
consideração que não é suficiente apresentar o vocabulário aos aprendentes uma só vez, visto que a aprendizagem do léxico, como será posteriormente explicitado, desenvolve-se de uma forma progressiva e gradual e, tal como indica Baralo (2007: 40):

En el aula necesitamos, por lo tanto, destinar tiempo para realizar tareas que ayuden a los alumnos a reciclar el léxico que ya conocen, por lo que el profesor necesita disponer de una tipología muy variada de tareas y de técnicas que faciliten ese reciclado del léxico y que eviten su desgaste o pérdida.

São várias as tipologias de atividades destinadas à aprendizagem do léxico, desde as mais formais, como relacionar o vocabulário com a sua definição, mediante o recurso a dicionários, por exemplo, às atividades de carácter lúdico que proporcionam uma forma motivadora para o desenvolvimento da competência lexical dos aprendentes, ao mesmo tempo que se desenvolvem outras destrezas, como a interação oral, a competência escrita, de leitura, a competência auditiva, entre outras.

Por sua vez, Cassany, Luna \& Sanz (1994: 388) propõem várias atividades, entre as quais se encontram algumas de cariz lúdico, tais como, o recurso a suportes gráficos, mediante a associação de léxico a imagens; a análise da morfolexicologia, i.e., dos processos de formação de palavras; a procura de derivações ou de palavras compostas a partir de uma raiz lexemática; o preenchimento de lacunas através de um exercício de compreensão de leitura, no qual o docente pode selecionar os espaços em branco arbitrariamente ou respeitando uma característica léxica ou gramatical; exercícios de relações semânticas, nos quais o estudante procura sinónimos, antónimos ou hiperónimos de uma determinada palavra isolada ou discriminar possíveis significados de uma palavra polissémica; elaboração de esquemas e organigramas como forma de revisão de uma determinada temática, de antecipação de uma leitura ou como fonte de informação para uma atividade de expressão oral ou escrita; e, por fim, um exercício de sinonímia contextualizada com base em textos completos ao invés de listas de palavras.

Os mesmos autores sugerem o recurso à literatura mediante a seleção de um texto breve no qual o docente possa eleger algumas palavras para que, posteriormente, os alunos procurem os sinónimos que permitam a sua substituição nesse contexto. Propõem, igualmente, a manipulação do texto de maneira a que uma palavra se repita várias vezes e que os alunos a substituam 
por um sinónimo. Os investigadores salientam, ainda, o papel dos materiais autênticos na aprendizagem de vocabulário como fonte de motivação para os aprendentes.

É possível depreender que o estudo do léxico deve incidir na revisão e repetição das unidades lexicais, assim como nas suas relações em vez de palavras isoladas. Uma forma de apresentar o léxico em contexto pode ser através de breves textos literários, nomeadamente a poesia.

\subsection{Texto em verso no desenvolvimento da competência lexical}

O papel do texto em verso na aquisição de vocabulário tem sido destacado e tem merecido atenção por parte de investigadores do campo anglo-saxónio e da língua espanhola. No que diz respeito ao desenvolvimento da competência lexical, estes sublinham a aceleração do enriquecimento dos conhecimentos sintáticos e semânticos através do texto literário:

Literature is replete with various vocabularies, sentence patterns, words-order and grammatical items which help the learners to learn the target language. Literature is also a good resource for increasing word power. In other words, literature involves a profound range of vocabulary, dialogues and prose. (Van, 2009, apud Khatib, 2011: 202)

A autenticidade dos textos literários prepara os aprendentes para situações comunicativas reais da língua-alvo: «Literature is inherently authentic and provides authentic input for language learning» (Khatib, 2011: 202), desenvolvendo os conhecimentos sociolinguísticos e pragmáticos dos aprendentes, que fazem parte da competência comunicativa: «Literature due to its authenticity is equipped with sociolinguistic and pragmatic information» (Khatib, 2011: 202).

O texto em verso, em particular, caracteriza-se pela sua riqueza linguística, assim como a variedade de estruturas sintáticas, estilísticas, construções morfológicas e formas de expressar ideias:

otro factor que hace de la poesía una herramienta esencial en un manual de este tipo de enseñanza es su riqueza lingüística, dado que constituye un incremento del vocabulario por parte del alumno que lee en lengua extranjera que le proporciona un rico bagaje léxico en fases avanzadas del aprendizaje; y el 
abanico de posibilidades a la hora de elegir un texto (...) es bastante abundante. (Melián, 2015:13)

Segundo Khatib (2011), o texto em verso pode revelar-se um recurso útil para a prática de estruturas gramaticais, sugerindo uma atividade na qual os aprendentes devem transformar estruturas complexas retiradas de um poema, em estruturas padrão da língua-alvo.

Contudo, alguns investigadores sublinham a complexidade lexical e sintática na literatura, tornando-a num objeto que faz «little or nothing to help students to become competent users of the target language» (Robson, 1989: 25, apud Khatib, 2011: 204), enquanto outros advogam que o texto literário possui vocabulário antigo e em desuso que não é utilizado na linguagem atual. Khatib (2011: 204) contrapõe que não é imperativo que o docente recorra a textos antigos, na medida em que existem «many modern literary texts that can be used as a source of input».

Também algumas palavras sofreram alterações semanticamente e estas diferenças no significado, para alguns investigadores, constituem um entrave na aplicação didática de textos literários no processo de ensino-aprendizagem de uma LE. Contudo, Khatib (2011) considera que as alterações semânticas não bloqueiam os conhecimentos prévios dos aprendentes, mas funcionam como um apêndice ao seu repertório semântico e acrescenta que, desde que o texto selecionado não esteja a impedir a aprendizagem da língua-alvo, não se prevê nenhuma inconveniência na sua aplicação didática.

A poesia, com toda a sua pluralidade, pode ser linguagem coloquial, quotidiana, ou hermética e complexa. No entanto, a sua elaboração estética permite o contacto com procedimentos cognitivos comuns e produtivos em situações comunicativas reais da língua quotidiana e coloquial, «podendo ajudar o aluno a ver e compreender o mundo dos falantes de uma comunidade e aceder à cultura da língua que se aprende» (Figliolo, 2016: 139), tendo em conta que, normalmente, expressa sentimentos e temas universais e carrega uma intenção comunicativa real dirigida a qualquer leitor.

Além disso, muitas vezes os textos que refletem situações pretensamente comunicativas transmitem uma linguagem estandardizada e fixa, tornando-se desmotivantes para os aprendentes e limitadores na aprendizagem, no sentido em que não espelham com naturalidade as interações comunicativas. Por outro lado, a função literária da linguagem oferece ao leitor uma experiência diferente da linguagem comum, uma vez que chama a atenção para as suas 
características formais: «Poets choose words not only for their senses, but also for sound, and the word pictures they create. The language of poetry makes senses and sound, rhythm, music, and vision, whereas ordinary language only makes sense» (Rezai, 2005: 5).

Autores como Rush (2011), Lanseros e Sánchez (2017) sustentam que a exposição ao texto em verso, para além de aumentar o corpus de vocabulário dos aprendentes, fomenta a capacidade de distinção entre os significados literais e simbólicos ou metafóricos: «Exposure to literature can increase students' vocabulary and understanding of linguistic structures and the more creative aspects of language, such as metaphor, symbolism, and imagery» (Rush, 2011: 75).

Embora seja frequente considerar a linguagem figurativa e o léxico utilizado demasiado complexos para os aprendentes, é importante lembrar que a linguagem metafórica é utilizada na vida quotidiana e que muitas expressões têm por base metáforas. Na opinião de Gustavo Figliolo (2016: 139), «Não existe razão, assim, para pensar que o aluno estrangeiro terá dificuldades intransponíveis para entender estas metáforas e esta linguagem figurativa, desde que seja dosada de maneira gradual». O mesmo acontece com outras figuras de estilo: «Recursos estilísticos e mecanismos expressivos como a ironia, a argumentação, o humor, etc. são de uso comum na poesia pelo que esta amplia a consciência linguística do aluno desde o primeiro contato com os textos poéticos» (Figliolo, 2016: 140).

Concluímos que são inúmeras as atividades ou tarefas que podem ser criadas ou adaptadas a partir deste género literário, de forma a trabalhar a competência comunicativa, a nível lexical. Nas palavras de Fernanda Barrocas:

Alargando o léxico, o aprendente melhora a compreensão oral e escrita; a oralidade e a escrita, por sua vez, tornar-seão mais fluentes. A capacidade imaginativa desenvolve-se, a possibilidade de recriar mundos sonhados acontece. (Barrocas, 2001: 21)

\section{Intervenção pedagógico-didática}

A nossa investigação teve lugar na Universidade Carolina de Praga, na República Checa em colaboração com o Centro de Língua Portuguesa - Instituto Camões de Praga, no ano letivo 2017/2018, no âmbito de um estágio pedagógico do Mestrado em Português Língua Segunda/Língua Estrangeira da Faculdade de Letras da Universidade do Porto. 
A turma da unidade curricular Seminário Lexical IV, no quarto semestre do curso de licenciatura de Estudos Portugueses, era constituída por seis elementos do sexo feminino, com um escalão etário compreendido entre os 20 e os 26 anos de idade, de nacionalidade checa. Todas as alunas se enquadravam num nível de proficiência $\mathrm{B} 1$, de acordo com a escala global do QECR e as principais línguas de interferência eram o francês e o inglês. Os objetivos de ensinoaprendizagem revelados pelas estudantes evidenciavam a expansão do vocabulário, tendo algumas estudantes especificado, mediante textos autênticos em língua portuguesa. As aprendentes demonstraram homogeneidade quanto ao gosto pela leitura, tanto na sua língua materna, como em língua portuguesa.

Selecionando os materiais adequados para o fim pretendido, avaliamos que seria possível desenvolver a competência lexical das aprendentes, recorrendo a poemas de autores contemporâneos de países de língua portuguesa. Assim, de acordo com o nível de proficiência das aprendentes que integravam a turma do Seminário Lexical IV, procuramos selecionar textos que fossem ao encontro dos interesses das alunas e abordassem temáticas úteis, atuais e que conduzissem à reflexão, fomentando o espírito crítico das aprendentes e a partilha de ideias em sala de aula. Pela sua brevidade, cada texto selecionado adequou-se convenientemente ao tempo disponível em cada unidade letiva ( 90 minutos).

Em cada unidade letiva foi apresentado um texto em verso que serviu como instrumento didático orientado para a exploração do léxico desconhecido, assim como de diversas temáticas lexicais. Os seis poemas selecionados para as seis unidades letivas do estágio pedagógico respondem às seguintes características: são variados na sua temática, de forma a englobar temas atuais e de interesse das alunas, assim como adequados ao contexto de lecionação; são linguisticamente adaptados às capacidades exigidas pelo nível de proficiência das estudantes; possuem potencialidades educativas, tendo em conta os objetivos programáticos da unidade curricular, tendo como foco o desenvolvimento da competência lexical; estão escritos tanto na variante do português europeu, como na variante do português do Brasil.

Na primeira unidade letiva foi apresentado à turma o poema «Porto Sentido», de Carlos Tê, a partir do qual se realizou a exploração do vocabulário e da linguagem simbólica, uma atividade didática de correspondência de palavras do poema a imagens e exercícios de sinonímia e antonímia de palavras da classe dos adjetivos. As alunas também transformaram três estrofes em prosa de forma a consolidar a compreensão da linguagem simbólica e transmitir por escrito o sentido que compreenderam. Para além disso, deram 
início à prática da leitura expressiva com foco no ritmo, pausas, expressividade e prosódia.

A segunda unidade letiva versou sobre a expansão do léxico pertencente à classe do nome, através da leitura e análise de um poema de Álvaro Magalhães, intitulado «O Limpa-palavras». Em primeiro lugar, as alunas realizaram uma atividade lúdica de transição do estudo de palavras da classe do adjetivo para a classe do nome - um dominó de palavras com adjetivos retirados do poema da aula anterior. Preencheram o poema «O Limpa-Palavras» com as palavras em falta, tendo em conta o sentido do verso e confirmaram as suas respostas mediante a escuta da declamação. Também realizaram uma atividade de expansão lexical em que deveriam propor um conjunto de palavras do campo lexical de alguns nomes comuns retirados do texto.

$\mathrm{Na}$ terceira unidade letiva as alunas começaram por escutar a versão musical do poema «Águas de Março» da autoria de Tom Jobim, e durante a audição selecionaram a palavra correta do final de alguns versos. Seguiu-se uma atividade lúdica (jogo da memória), de associação de várias palavras retiradas do poema a imagens e um momento dedicado ao esclarecimento de dúvidas de vocabulário, tanto do poema na íntegra, como das palavras que foram adicionadas ao exercício de audição. Importa assinalar que a seleção de um poema escrito em português do Brasil deve-se ao interesse das aprendentes por esta variante e como forma de promover o reconhecimento das várias variantes da língua portuguesa.

A quarta unidade letiva incidiu na consolidação do estudo do discurso direto e indireto e para isso foi selecionado um poema de Alberto Janes, intitulado «Ao Poeta Perguntei», que está escrito em forma de diálogo e que apresenta marcas de registo oral comuns em situações comunicativas da língua-alvo, assim como verbos de elocução que introduzem o discurso indireto. Como pré-atividade, as alunas escutaram a interpretação musical do poema pela fadista Amália Rodrigues e completaram os espaços em branco, desenvolvendo a sua sensibilidade auditiva. As alunas realizaram dois exercícios com léxico relacionado com o género musical português fado.

$\mathrm{Na}$ quinta unidade letiva, que coincidiu com as celebrações do 25 de abril, as alunas exploraram vocabulário relacionado com Liberdade e Revolução e nomes de flores e plantas a partir de um poema intitulado «Portugal Ressuscitado» da autoria de Ary dos Santos. Começaram por escutar a interpretação musical do poema e durante a escuta detetaram a palavra que não correspondia ao texto 
original. Após o esclarecimento de dúvidas sobre o vocabulário desconhecido, realizaram uma ficha de trabalho onde constavam exercícios de expansão lexical como palavras cruzadas e um acróstico e uma atividade lúdica de associação de alguns nomes de flores e plantas a imagens.

A última unidade letiva versou sobre as relações interpessoais e vocabulário relativo a árvores de fruto através de uma atividade lúdica dando seguimento ao exercício da aula anterior sobre os nomes de flores e plantas. O poema selecionado, «A Banda», de Chico Buarque, contribuiu para a realização de exercícios de exploração de léxico relacionado com a temática acima mencionada, assim como para explorar algumas expressões que apresentassem um segundo sentido.

\section{Resultados}

A partir da análise dos resultados dos questionários respondidos pelas aprendentes foi possível concluir que, no geral, as mesmas consideraram as atividades propostas úteis, em especial, os exercícios direcionados para a expansão lexical.

O número total das aprendentes considerou úteis e eficazes as estratégias, exercícios e atividades adotadas para trabalhar o léxico, tais como, exercícios de campos lexicais, relações semânticas e atividades lúdicas, assim como exercícios de interpretação aberta, de descodificação do sentido de expressões fixas, de audição e leitura expressiva. Importa sublinhar que as estudantes referiram a aprendizagem de vocabulário útil para situações comunicativas do dia-a-dia e de vocabulário associado à linguagem literária.

No que diz respeito à seleção dos poemas, todas as estudantes consideraram os poemas interessantes, especificando o seu interesse pelas temáticas abordadas, assim como o seu agrado pela abordagem de acordo com um tema relacionado com o poema em questão e pela seleção de um género textual cuja presença nas restantes aulas de português língua estrangeira, segundo as aprendentes, não é comum.

Compreendemos, assim, que as propostas pedagógico-didáticas desenvolvidas ao longo do semestre neste conjunto de unidades letivas, bem como as estratégias e metodologias aplicadas e as atividades de léxico implementadas (atividades de memorização, de associação de palavras a imagens e as várias fichas de trabalho), apresentaram resultados positivos, tal como é possível constatar mediante a análise dos resultados dos elementos de avaliação, da observação 
direta e das respostas das aprendentes ao último questionário sobre a disciplina Seminário Lexical IV. Este sucesso educativo foi, de igual forma, resultado da motivação das aprendentes face à leitura e escuta de poemas e do seu interesse constante pela aprendizagem de léxico.

Para além disso, a partir dos resultados obtidos no teste de avaliação formativa, foi possível analisar que os objetivos estipulados ao longo do semestre foram atingidos, no que diz respeito ao desenvolvimento da competência lexical das estudantes, aliado ao desenvolvimento da competência gramatical, tendo em conta que a abordagem ao léxico foi realizada de forma intercalar com a consolidação de conteúdos gramaticais ${ }^{1}$.

\section{Considerações finais}

Pretendemos com este artigo demonstrar que o texto poético deve dispor do seu merecido lugar em contexto de sala de aula e valorizar aquelas características que, a nosso ver, fazem com que o consideremos um género privilegiado no desenvolvimento de determinadas competências educativas no processo de ensino-aprendizagem de uma LE.

Podemos concluir que o léxico contribui para um bom desempenho da línguaalvo, visto que, naturalmente, os estudantes de uma LE procuram desde os primeiros níveis de aprendizagem compreender o sentido das palavras, de forma a adquirir um nível de proficiência que permita usar a língua no discurso e que o texto em verso pode contribuir para o desenvolvimento da competência lexical no processo de ensino-aprendizagem de uma LE.

Neste sentido, elaboramos exercícios diversificados e fomos ao encontro das recomendações feitas por Cassany, Luna \& Sanz (1994), entre outros autores mencionados, selecionando um material autêntico, de cariz literário, como um texto breve, produzindo exercícios de relações semânticas e atividades lúdicas como jogos de associação de imagens, assim como exercícios de interpretação aberta e de descodificação do sentido de expressões fixas.

Resta-nos sublinhar, uma vez mais, a importância da integração do texto em verso na aula de LE, uma vez que a experiência descrita ao longo do presente artigo nos demonstra que este tipo de recurso, adequadamente explorado,

1 Tivemos em conta a indissociabilidade entre o campo lexical e o campo gramatical sustentada por Rio-Torto: "léxico e gramática são como que duas faces na mesma realidade, contribuindo de forma complementar para a chamada competência léxico-gramatical dos falantes" (2006: 11). 
potencia o processo de ensino-aprendizagem, não só no que diz respeito ao domínio linguístico, mas também no que respeita ao enriquecimento da formação cultural e humana e na estimulação da criatividade e da consciência crítica dos aprendentes.

\section{Referências bibliográficas}

Baralo, M. (2007): «Adquisición de palabras: Redes semánticas y léxicas». Actas del programa de formación para profesorado de español como lengua extranjera. Instituto Cervantes de Munich: http://cvc.cervantes.es/ensenanza/ biblioteca_ele/publicaciones_centros/PDF/m nich_20 06-2007/04_baralo.pdf (30-05-2019).

Barrocas, F. (2001): «O texto literário na aula de português língua estrangeira - da estranheza ao deslumbramento». Revista Aprender 25, 18-21.

Cassany, D.; Luna, M., Sanz, G. (1994): Enseñar lengua. Barcelona: Graò.

Cervero, M. J., Castro P. F. (2000): Aprender y enseñar vocabulario. Madrid: Edelsa/ Grupo Didascalia.

Conselho da Europa. (2001): Quadro Europeu Comum de Referência para as Linguas: Aprendizagem, Ensino, Avaliação. Porto: ASA Editores II, S.A.

Figliolo, G. (2016): «Ensino de línguas estrangeiras: A Poesia Como Recurso Didático». Entrelínguas, 2 (1), 125-142.

Jiménez Catalán, R.M. (2002): «El concepto de competencia léxica en los estudios de aprendizaje y enseñanza de segundas lenguas». Atlantis, 2002, vol. $\operatorname{XXIV(2),~149-162.~}$

Khatib, M. (2011): «Literature in EFL/ESL classroom». English Language Teaching, 4 (1), 201-208.

Lanseros, R., Sánchez, M.R. (2017): «La poesía en el aula de español como lengua extranjera. Propuesta didáctica para el nivel avanzado de EEOOII a partir de un poema de Antonio Colinas». La poesía en el aula de español, 26, 91-112.

Meara, P. (1996): «The dimensions of lexical competence». Journal of Language Teaching and Research, 8(2), 205-213.

Melián, J.E.G. (2015): Propuesta didáctica de un texto poético en un aula de ELE. La Laguna: Universidad de la Laguna.

Morante, R. (2005): El desarrollo del conocimiento léxico en segundas lenguas. Madrid: Arco/Libros. 
Naranjo, M. (1999): La poesía como instrumento didáctico en el aula de español como lengua extranjera. Madrid: Edinumen.

Oliveira, B. (2018): O texto em verso no desenvolvimento da competência lexical em PLE. Trabajo de fin de máster. Porto: Faculdade de Letras da Universidade do Porto.

Rio-Torto, G. (2006). «O Léxico: semântica e gramática das unidades lexicais». En: Maria Francisca Athayde (coord.), Estudos sobre léxico e gramática. Coimbra: Cadernos do Cieg n ${ }^{0}$ 23, 11-34.

Rush, P. (2011): Bebind the Lines: Using Poetry in the Language Classroom: http:// library.nakanishi.ac.jp/kiyou/gaidai(30)/05.pdf (25-05-2019).

Vilela, M. (1994): Estudos de Lexicologia do Português. Coimbra: Livraria Almedina.

Vilela, M. (1995): Léxico e gramática, Ensino da lingua portuguesa: léxico, dicionário, gramática. Lisboa: Livraria Almedina.

Wilkins, D. A. (1972): Linguistics and Language Teaching. Londres: Edward Arnold. 
Beatriz Moreira de Oliveira

University of Porto

\section{Poetry text in verse in the development of lexical competence in a Portuguese as a foreign language}

Keywords: poetry text, lexicon, vocabulary, lexical competence, Portuguese as a foreign language

The purpose of this article is to reflect on the use of poetry in the process of teaching and learning Portuguese as a foreign language; more specifically, in the development of lexical competence. Our aim is to reveal the potential of poetry with regard to the creation of exercises of lexical expansion, and we specify in which ways the features of poetry may contribute to the development of lexical competence. We analyse the concepts of lexicon, vocabulary and lexical competence, while examining their approach in the Common European Framework of Languages (2011), and we point out several strategies to develop this competence in foreign language class. We present a pedagogical and didactical intervention which took place in the module Lexical Seminar $I V$ at Charles University of Prague, Czech Republic, in the academic year of 2017/2018, and we detail the context and selected methodologies, the didactic proposals applied, as well as the results obtained and the effectiveness of the performed intervention. 
Beatriz Moreira de Oliveira

Univerza v Portu

\section{Pesniško besedilo pri razvoju besedilne kompetence pri predmetu tuji jezik}

Ključne besede: pesniško besedilo, leksika, besedišče, besedilna kompetenca, portugalščina kot tuji jezik

$\mathrm{V}$ pričujočem članku razmišljamo o vključitvi pesniškega besedila v proces učenja in poučevanja portugalščine kot tujega jezika oz. o razvoju učenčeve besedilne kompetence. Naš namen je prikazati možnosti, ki jih za pripravo vaj za širitev besedišča ponuja pesniško besedilo, in opisati, na kakšen način lahko značilnosti pesniškega besedila prispevajo k razvoju besedilne kompetence. Analiziramo koncepte leksikona, besedišča in besedilne kompetence, kot jih opredeljuje Skupni evropski jezikovni okvir (2001), in orišemo glavne strategije za razvoj te kompetence pri pouku tujega jezika. Predstavimo pedagoško didaktično dejavnost, ki je $\mathrm{v}$ študijskem letu 2017/2018 potekala pri predmetu Leksikalni seminar IV na Karlovi univerzi v Pragi, Češki republiki, in razmišljamo o strategijah, metodologijah, uporabljenih didaktičnih ciljih kot tudi o dobljenih rezultatih in o učinkovitosti našega posega. 